\title{
The Colour Characteristics of Gold Alloys
}

\author{
Errol F. I. Roberts and Keith M. Clarke
}

Department of Metallurgy and Materials, City of London Polytechnic, London

\begin{abstract}
The characterisation by physical methods of the colour of gold alloys is of particular significance to industries which use them on account of their aesthetic qualities. In this article, the authors describe the systematic determination of the colour of alloys in the gold-silver-copper system. It embodies unpublished data which should be useful for future investigations.
\end{abstract}

As a result of subjective assessment, different colour descriptions may be applied to gold alloys of the same or very similar compositions (1). There thus appears to be a definite need to place the colour characterisation of such alloys - which are often used for aesthetic and decorative purposes - on a sound basis. Over recent years, colour standards have been developed that have relied upon a straightforward sample comparison technique. The most notable of these is the German DIN 8238 which is an extension of an earlier Swiss watch industry standard. This is based upon a series of 18 and 14 carat gold alloys ranging from red to white through green and yellow (Table I) and assessment is performed by visual comparison with test pieces. It is simple and convenient but is qualitative, imprecise, highly subjective and does not provide a basis for judging colours outside the arbitrary standard specimens. More recently, this limited number of specimens has been examined quantitatively in a manner not dissimilar to that reported in this article.

Few fundamental colorimetric studies of gold alloys are reported in the literature, possibly as a result of inadequate instrumentation being available in the past. In 1949, Josef Leuser of Degussa in Pforzheim, Germany, published (2) a diagram of the ternary goldsilver-copper system in which the alloy field was divided into areas with named colours. This report was based on a very extensive visual examination of manufactured alloys and Leuser mentions in this connection that some years earlier, 1089 different alloys covering the full range of compositions of the ternary system had been prepared in the Degussa laboratories in Pforzheim. From each of these 1089 alloys a piece of foil, in the shape of an equilateral triangle, was fabricated and the pieces were assembled in a large triangle, $1 \mathrm{~m}$ in side-length. This historic colour chart of the gold-silver-copper system was unfortunately destroyed in World War II. Due credit should also be given to Tammann $(3,4)$ who made similar but much more limited observations from 1917 to 1919. Subsequently, E. M. Wise (5) reproduced the Leuser diagram and, in translation, a few modifications were made to the colour descriptions. This is not surprising as such descriptions are notoriously difficult.

Since colorimetry (the science of colour measurement) is fast becoming a well-established and scientifically sound field, it seemed reasonable to try and apply conventional colorimetric procedures to the gold-silver-copper system. Indeed, $\operatorname{Gardam}(6,7)$ did carry out some preliminary studies of a range of metals using a small EEL tristimulus photometer. $\mathrm{He}$ demonstrated the important facts that metals are
Table I

Standard Colours Adopted for Watchcases

\begin{tabular}{|c|c|c|c|c|c|c|c|}
\hline \multirow[t]{2}{*}{ Colour coding } & \multirow[t]{2}{*}{$\begin{array}{l}\text { Colour } \\
\text { description }\end{array}$} & \multirow[t]{2}{*}{ Carat } & \multicolumn{5}{|c|}{$\begin{array}{l}\text { Composition of the corresponding } \\
\text { reference alloy, parts per thousand }\end{array}$} \\
\hline & & & $\mathrm{Au}$ & $\mathrm{Ag}$ & $\mathrm{Cu}$ & $\mathrm{Ni}$ & $\mathrm{Zn}$ \\
\hline $1 \mathrm{~N}-14^{\star}$ & Pale yellow & 14 & 585 & 265 & 150 & - & - \\
\hline $2 \mathrm{~N}-18^{\star}$ & Pale yellow & 18 & 750 & 160 & 90 & - & - \\
\hline $3 \mathrm{~N}^{\star}$ & Yellow & 18 & 750 & 125 & 125 & - & - \\
\hline $4 \mathrm{~N}^{\star}$ & Rose (pink) & 18 & 750 & 90 & 160 & - & - \\
\hline $5 \mathrm{~N}^{\star}$ & Red & 18 & 750 & 45 & 205 & - & - \\
\hline $0 N^{\star \star}$ & Yellow-green & 14 & 585 & 340 & 75 & - & - \\
\hline $8 N^{\star \star}$ & White & 14 & 590 & - & 220 & 120 & 70 \\
\hline
\end{tabular}

* Standards common to Germany, France and Switzerland

$\star \star$ Standards common to Germany and France 
(1) Highly desaturated

(2) Of a limited range of dominant wavelengths

(3) Of very high luminance.

Desaturated colours are pale in hue. Any given colour can be reproduced by mixing 'white' light with an appropriate proportion of spectrally pure light. Different proportions give a range of saturation from white, pastel shades to the spectrally pure shade which is the most intense colour of that particular hue available. The term saturation is used here in the sense of the proportion of spectrally pure colour in the mixture. The dominant wavelength is the wavelength of the particular spectrally pure colour needed to match the colour and hence describes the hue. Luminance is a technical term which will be mathematically defined below and which correlates well with brightness. In black and white photography, objects having higher luminance will record as whiter than objects having lower luminance. Colour terminology is a confusing area and the in terested reader would be well advised to consult a standard text such as (18).

Reflectance spectrophotometers are now available that can give both specular and diffuse reflectance measurements from metal surfaces and reflectivity data have been reported on a number of binary gold alloys ( 8 to 11). In the present work, use was made of the spectro-ellipsometer to collect data upon specular reflections. A systematic series of suitable alloys was prepared and the optical characteristics of standard samples made from the alloys were measured. The system chosen to be examined was the gold-silver-

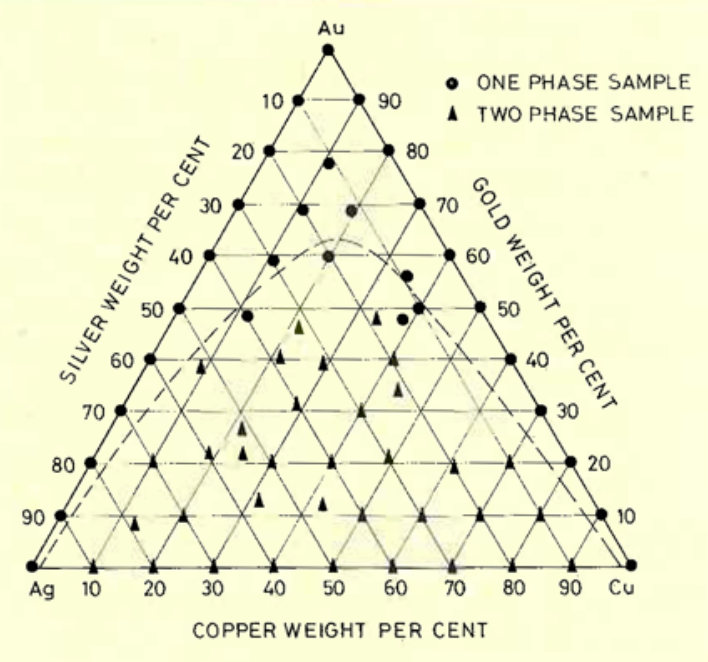

Fig. 1 Relationship between the composition and the number of phases present in binary and ternary alloys of the gold-silver-copper system after water quenching from $600^{\circ} \mathrm{C}$. The dotted line is the $600^{\circ} \mathrm{C}$ isothermal boundary of the immiscibility field as determined by McMullin and Norton (13) copper ternary system, upon which the development and manufacture of jewellery alloys is based. Briefly, 66 flat polished samples of compositions 10 per cent by weight apart were examined by spectroellipsometry and the dispersion of their optical constants were calculated. These in turn were used to determine reflection characteristics and Comité International de l'Eclairage (CIE) colour co-ordinates.

\section{The Metallurgy of the Gold-Silver-Copper Ternary System}

The gold-silver-copper metallurgical system consists of two binary complete solid solutions, goldsilver and gold-copper, and one eutectic system, silver-copper, the latter with very restricted solubilities in the terminal solid solutions, especially at room temperature. As a consequence of these features, at any temperature in the solid range, the ternary system shows either a two-phase region, based upon the phases present in the silver-copper eutectic system, or a single-phase ternary solid solution. The equilibrium two-phase region extends towards the gold-rich corner of the ternary system as the equilibrium temperature falls. Finally, the orderdisorder reactions associated with the gold-copper binary alloys intrude into the ternary alloy field close to the binary compositions and the gold-silver system also displays some short-range ordering. A detailed discussion of the system is available elsewhere (12).

The 66 alloys examined in this study were made up from fine gold, fine silver and spectrographically pure copper at 10 per cent by weight composition intervals. Alloy melting was carried out in a carbon crucible in a r.f. induction furnace under an inert gas atmosphere. After casting under oil, the resulting bead was worked into flat sheet with intermediate homogenizing and fully softening anneals. Final shaping produced flat rectangular plaquettes which were again annealed at $600^{\circ} \mathrm{C}$ and water quenched. Subsequently, these samples were mounted and metallographically polished down to $0.25 \mu \mathrm{m}$ diamond paste. The alloys were assayed and examined by X-ray diffraction (Table II). Examinations for flatness, roughness and phase composition were also conducted. Figure 1 compares the single- and duplexphase regions for the $600^{\circ} \mathrm{C}$ isothermal section as determined by X-ray diffraction after water quenching in a previous investigation (13) and in the course of the present work. The effect of the water quench is to retain the $600^{\circ} \mathrm{C}$ equilibrium structure and to prevent ordering transformations.

\section{Basic Optics of Solids}

Elementary optics $(14,15)$ demonstrates that a monochromatic ray of light meeting a surface at some 


\section{Table II}

Composition and Lattice Parameters of the Binary and Ternary Alloys in the Gold-Silver-Copper System used in This Study. All the Alloys were Quenched in Water from $600^{\circ} \mathrm{C}$

\begin{tabular}{|c|c|c|c|c|c|c|c|c|c|}
\hline $\begin{array}{l}\text { Alloy } \\
\text { No. (*) }\end{array}$ & $\begin{array}{l}\mathrm{Au} \\
\text { Compositi }\end{array}$ & $\begin{array}{c}\mathrm{Ag} \\
\mathrm{n}, \text { weight } \mathrm{p}\end{array}$ & $\begin{array}{c}\mathrm{Cu} \\
\operatorname{cent}(\dagger, \neq)\end{array}$ & $\begin{array}{c}\text { Lattice } \\
\text { parameter (8) } \\
\AA\end{array}$ & $\begin{array}{l}\text { Alloy } \\
\text { No. }\left(^{\star}\right)\end{array}$ & $\begin{array}{c}\mathrm{Au} \\
\text { Composi }\end{array}$ & n, weight & $\begin{array}{c}\mathrm{Cu} \\
\mathrm{r} \operatorname{cent}(t, \neq)\end{array}$ & 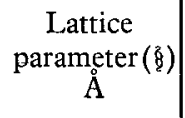 \\
\hline $1 \mathrm{R}$ & $-(0)$ & - & $100(100)$ & 3.610 & 43 & $39.0(40)$ & $30.8(30)$ & $30.2(30)$ & 4.033 \\
\hline 2 & $9.9(10)$ & - & $90.1(90)$ & $3.636(7)$ & & & & & 3.780 \\
\hline 3 & $18.2(20)$ & - & $81.8(80)$ & 3.664 & 44 & $40.4(40)$ & $19.6(20)$ & $40.0(40)$ & 4.038 \\
\hline 4 & $31.2(30)$ & - & $68.8(70)$ & 3.684 & & & & & 3.767 \\
\hline 5 & $34.9(40)$ & - & $65.1(60)$ & 3.733 & 45 & $48.5(40)$ & $11.5(10)$ & $39.1(50)$ & 3.801 \\
\hline 6 & $48.5(50)$ & - & $51.5(50)$ & 3.758 & $45 \mathrm{R}$ & $39.9(40)$ & $10.7(10)$ & $49.5(50)$ & n.a. \\
\hline 7 & $63.1(60)$ & - & $36.9(40)$ & 3.785 & 46 & $21.0(30)$ & $54.5(60)$ & $24.2(10)$ & 4.049 \\
\hline 8 & $70.0(70)$ & - & $30.0(30)$ & 3.835 & & & & & 3.723 \\
\hline $9 \mathrm{R}$ & $80.3(80)$ & - & $19.8(20)$ & n.a. & $46 R$ & $29.9(30)$ & $59.9(60)$ & $10.1(10)$ & n.a. \\
\hline $10 \mathrm{R}$ & $89.5(90)$ & - & $10.5(10)$ & 4.004 & 47 & $27.3(30)$ & $51.0(50)$ & $21.5(20)$ & 4.047 \\
\hline $11 \mathrm{R}$ & $99.98(100)$ & - & - $\quad(0)$ & 4.062 & & & & & 3.782 \\
\hline 12 & - & $89.5(90)$ & $10.5(10)$ & $\begin{array}{c}4.049 \\
3.620(3)\end{array}$ & 48 & $30.5(30)$ & $39.7(40)$ & $29.8(30)$ & $\begin{array}{l}4.051 \\
3.747\end{array}$ \\
\hline 13 & - & $79.9(80)$ & $20.1(20)$ & $\begin{array}{c}4.061 \\
3.630(3)\end{array}$ & 49 & $30.0(30)$ & $29.9(30)$ & $40.1(40)$ & $\begin{array}{l}4.052 \\
3.727\end{array}$ \\
\hline 14 & - & $69.2(70)$ & $30.8(30)$ & $\begin{array}{l}4.056 \\
3.625\end{array}$ & 50 & $33.3(30)$ & $20.7(20)$ & $46.0(50)$ & $\begin{array}{l}4.045 \\
3.744\end{array}$ \\
\hline 15 & - & $60.8(60)$ & $39.2(40)$ & $\begin{array}{l}4.047 \\
3.620\end{array}$ & 51 & $29.9(30)$ & $9.6(10)$ & $60.5(60)$ & $\begin{array}{l}4.046 \\
3.708\end{array}$ \\
\hline 16 & - & $50.3(50)$ & $49.7(50)$ & $\begin{array}{l}4.050 \\
3.621\end{array}$ & 52 & $20.2(20)$ & $69.7(70)$ & $10.1(10)$ & $\begin{array}{l}4.047 \\
3.734\end{array}$ \\
\hline 17 & - & $39.9(50)$ & $60.1(60)$ & $\begin{array}{l}4.049 \\
3.621\end{array}$ & 53 & $21.0(20)$ & $59.6(60)$ & $19.4(20)$ & $\begin{array}{l}4.043 \\
3.727\end{array}$ \\
\hline 18 & - & $30.1(30)$ & $69.9(70)$ & $\begin{array}{l}4.050 \\
3.620\end{array}$ & 54 & $19.9(20)$ & $49.8(50)$ & $30.3(30)$ & $\begin{array}{l}4.048 \\
3.704\end{array}$ \\
\hline 19 & - & $19.4(20)$ & $80.6(80)$ & $\begin{array}{l}4.062 \\
3.624\end{array}$ & 55 & $20.2(20)$ & $39.6(40)$ & $40.4(40)$ & $\begin{array}{l}4.052 \\
3.691\end{array}$ \\
\hline 20 & - & $10.6(10)$ & $89.4(90)$ & $\begin{array}{l}4.048 \\
3.618\end{array}$ & 56 & $20.5(20)$ & $29.8(30)$ & $49.7(50)$ & $\begin{array}{l}4.051 \\
3.689\end{array}$ \\
\hline 21 & $90.2(90)$ & $9.8(10)$ & - & 4.065 & 57 & $19.7(20)$ & $20.1(20)$ & $60.2(60)$ & 4.049 \\
\hline 22 & $80.0(80)$ & $20.0(20)$ & - & 4.065 & & & & & 3.677 \\
\hline 23 & $70.2(70)$ & $29.8(30)$ & - & 4.070 & 58 & $20.0(20)$ & $9.8(10)$ & $69.2(70)$ & 4.047 \\
\hline 24 & $60.2(60)$ & $39.8(40)$ & - & 4.071 & & & & & 3.673 \\
\hline 25 & $50.0(50)$ & $50.0(50)$ & - & 4.079 & 59 & $9.4(10)$ & $79.0(80)$ & $11.6(10)$ & 4.046 \\
\hline 26 & $39.9(40)$ & $60.1(60)$ & - & 4.074 & & & & & 3.678 \\
\hline 27 & $30.0(30)$ & $70.0(70)$ & - & 4.074 & 60 & $9.9(10)$ & $69.9(70)$ & $20.2(20)$ & 4.045 \\
\hline 28 & $20.6(20)$ & $79.4(80)$ & - & 4.075 & & & & & 3.666 \\
\hline $29 \mathrm{R}$ & $10.1(10)$ & $89,9(90)$ & - & 4.079 & 61 & $13.6(10)$ & $55.7(60)$ & $30.7(30)$ & 4.050 \\
\hline $30 \mathrm{R}$ & $-(0)$ & $99.97(100)$ & - & 4.083 & & & & & 3.666 \\
\hline 31 & $78.9(80)$ & $10.4(10)$ & $10.7(10)$ & 3.975 & 62 & $11.5(10)$ & $46.4(50)$ & $42.1(40)$ & 4.054 \\
\hline 32 & $69.9(70)$ & $10.6(10)$ & $19.5(20)$ & 3.902 & & & & & 3.662 \\
\hline 33 & $69.8(70)$ & $20.3(20)$ & $9.8(10)$ & 3.985 & 63 & $10.1(10)$ & $20.0(20)$ & $69.9(70)$ & 4.053 \\
\hline 34 & $59.6(60)$ & $29.8(30)$ & $10.6(10)$ & 3.981 & & & & & 3.650 \\
\hline 35 & $60.1(60)$ & $20.0(20)$ & $19.9(20)$ & 3.916 & 64 & $9.9(10)$ & $29.8(30)$ & $60.3(60)$ & 4.058 \\
\hline 36 & $56.1(60)$ & $9.7(10)$ & $34.2(30)$ & 3.868 & & & & & 3.658 \\
\hline 37 & $49.0(50)$ & $40.4(40)$ & $10.6(10)$ & 3.989 & 65 & $9.8(10)$ & $10.3(10)$ & $79.9(80)$ & 4.053 \\
\hline 38 & $48.1(50)$ & $31.2(30)$ & $20.7(20)$ & 3.995 & & & & & 3.665 \\
\hline 39 & $49.4(50)$ & $18.8(20)$ & $31.8(30)$ & $\begin{array}{l}3.872 \\
4.017 \\
3.812\end{array}$ & 66 & $9.9(10)$ & $39.8(40)$ & $50.3(50)$ & $\begin{array}{l}4.055 \\
3.648\end{array}$ \\
\hline 40 & $50.2(50)$ & $9.9(10)$ & $39.9(40)$ & 3.789 & \multirow{3}{*}{\multicolumn{5}{|c|}{$\begin{array}{l}\text { ^ } R \text { corresponds to repeat casts } \\
\dagger \text { The figures in parenthesis are nominal compositions } \\
\text { † The figures in italics were determined by difference } \\
\$ \text { The lattice parameters given here are the average of three calculations. } \\
\text { Alloys } 12 \text { to } 20,38 \text { to } 39,41 \text { to } 44 \text { and } 46 \text { to } 66 \text { were found to consist of two } \\
\text { phases. Accordingly, two lattice parameters were determined for these } \\
\text { alloys. }\end{array}$}} \\
\hline 41 & $39.3(40)$ & $51.2(50)$ & $9.5(10)$ & $\begin{array}{l}4.018 \\
3.829\end{array}$ & & & & & \\
\hline 42 & $40.4(40)$ & $39.0(40)$ & $20.6(20)$ & $\begin{array}{l}4.021 \\
3.801\end{array}$ & & & & & \\
\hline
\end{tabular}

angle of incidence $\theta_{\mathrm{i}}$ is generally partly reflected and partly transmitted. Furthermore, the transmitted beam is refracted or deviated from its original direction so that it makes some angle $\theta_{r}$ with the surface. Bearing in mind the electromagnetic-wave nature of light it is not surprising that this effect of an interface on light is predicted by Maxwell's electromagnetic theory and was empirically established by Snell. Basically, the behaviour is described by the set of equations: 


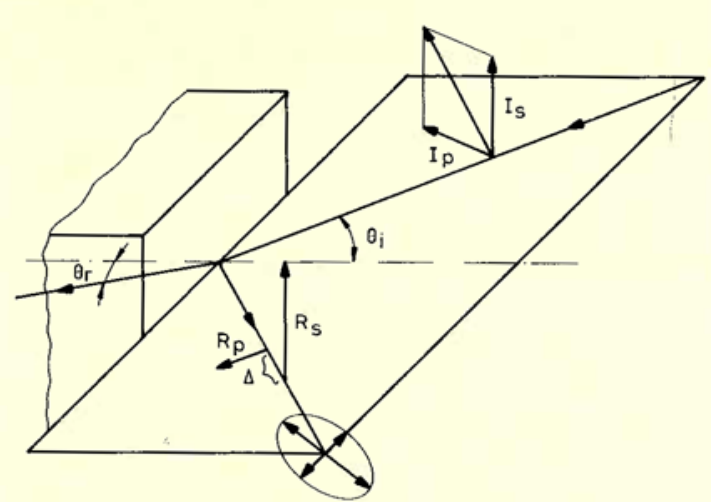

Fig. 2 This schematic diagram of the reflection and refraction of a polarised light beam at a metal surface shows selective absorption and phase retardation $\Delta$ between components parallel $(p)$ and perpendicular (s) to the plane of incidence

$$
\frac{\sin \theta_{\mathrm{i}}}{\sin \theta_{\mathrm{r}}}=\frac{\eta_{2}}{\eta_{1}}=\frac{\mathrm{c} / \nu_{2}}{\mathrm{c} / \nu_{\mathrm{I}}}=\frac{\left(\varepsilon_{2} \mu_{2}\right)}{\left(\varepsilon_{1} \mu_{1}\right)}
$$

where:

$\eta$ is the refractive index

$\varepsilon$ is the dielectric constant

$\mu$ is the magnetic permeability

$\mathrm{c}$ is the velocity of light in vacuum

$v$ is the velocity of light propagation in the particular medium

the subscripts 1 and 2 refer to the incident and refracting media respectively.

The manner in which light is reflected at an interface depends upon the state of polarisation of the light, the angles $\theta_{i}$ and $\theta_{r}$ and upon $\eta_{1}$ and $\eta_{2}$. The equations expressing this phenomenon were derived by the French mathematician Fresnel in 1823. Importantly, besides a change in amplitude occuring upon reflection, a phase change $\Delta$ is also introduced (Figure 2). For light polarised parallel to the plane of incidence (p-polarisation) and perpendicular to the plane of incidence (s-polarisation) and with incident amplitudes respectively $A_{p}$ and $A_{s}$ the relevant equations are:

$$
\begin{aligned}
& \mathrm{R}_{\mathrm{p}}=\frac{\eta_{2} \cos \theta_{\mathrm{i}}-\eta_{1} \cos \theta_{\mathrm{r}}}{\eta_{2} \cos \theta_{\mathrm{i}}+\eta_{1} \cos \frac{\theta_{\mathrm{r}}}{\mathrm{r}_{\mathrm{p}}}} \cdot \mathrm{A}_{\mathrm{p}} \\
& \mathrm{R}_{\mathrm{s}}=\frac{\eta_{1} \cos \theta_{\mathrm{i}}-\eta_{1} \cos \theta_{\mathrm{s}}}{\eta_{1} \cos \theta_{\mathrm{i}}+\frac{\eta_{2} \cos \theta_{\mathrm{r}}}{A_{\mathrm{s}}}} \cdot A_{\mathrm{s}}
\end{aligned}
$$

For normal incidence, $\theta_{i}=0$, consequently $\theta_{r}=0$ and

$$
\begin{aligned}
& \mathrm{R}_{\mathrm{p}}=\frac{\eta-1}{\eta+1}, \mathrm{~A}_{\mathrm{p}} \\
& \mathrm{R}_{\mathrm{s}}=\frac{\eta-1}{\eta+1} \quad . \mathrm{A}_{\mathrm{p}}
\end{aligned}
$$

where:

$\eta$ is the ratio $\eta_{2} / \eta_{1}$.

The reflectance $R$ is the ratio of the light flux $J_{r}$ reflected from a surface to the light flux $\mathrm{J}_{\mathrm{i}}$ incident upon that surface:

$$
\mathrm{R}=\frac{\mathrm{J}_{\mathrm{r}}}{\mathrm{J}_{\mathrm{i}}}
$$

While $\mathrm{R}$ depends upon the $\mathrm{p}$ - and s-polarisation, at normal incidence the distinction disappears and the normal reflectance becomes

$$
\mathrm{R}_{\mathrm{n}}=\left(\frac{\eta-1}{\eta+1}\right)^{2}
$$

where:

the subscript $\mathbf{n}$ refers to normal incidence.

It will be appreciated that if the refractive index is a function of wavelength then so too will be the reflectance. This wavelength-dependent function of the reflectance is called the reflectivity $R(\lambda)$.

It may be shown that the basic equations presented above apply to a conducting medium (such as a metal) if the real quantities of dielectric constant $\varepsilon$ and refractive index $\eta$ are replaced by the complex quantities $\bar{\varepsilon}$ and $\bar{\eta}$. For metals which have complex refractive indices, $\bar{\eta}=\eta-\mathrm{ik}$, where $\eta$ is the refractive index and $\mathrm{k}$ is the absorption coefficient. Thus,

$$
\mathrm{R}_{\mathrm{n}}=\frac{\eta^{2}+\mathrm{k}^{2}+1-2 \eta}{\eta^{2}+\mathrm{k}^{2}+1+2 \eta}
$$

A generalisation for oblique incidence is also easily established. In particular, the boundary conditions for propagation across a surface discontinuity remain valid and so do the laws of reflection and refraction. It becomes then a relatively simple matter to determine $\eta$ and $\mathrm{k}$ for a clean metal surface by measuring amplitude and phase quantities for the polarisation components of polarised light reflected from it.

Metals, it will be readily appreciated from their excellent electrical conductivities, possess electrons in energy states which are affected by applied electric fields. These electrons are the conduction electrons but other electrons are also susceptible to such fields and this is particularly so in metals where electron band overlapping occurs. The conduction electrons act very much like free electrons and consequently their optical effects dominate in parts of the spectrum where reflectance is high. The electrons capable of interband transition super-pose their high absorption on the spectrum.

\section{Colorimetry and its Application to Metals}

The perception of an object colour by the eye is determined by the nature and attributes of the light 
entering the eye and the nature of the observer. Translating instrumental readings into a form that corresponds to a visual perception demands at this stage consideration of the observer, and hence more generally the standard observing or colour detecting characteristics of the average eye. Once a set of characteristics has been agreed upon, colour determinations may be made which are independent of the colour vision of any particular individual and can be compared in independent laboratories. This involves setting up agreements on two issues - the response of tristimulus colour perception of a normal observer and the specific reference stimuli, or illuminants. The distribution coefficients relative to these standards and giving the amounts of three stimuli required to match colours through the spectrum can then be expressed. Agreement in these areas is now international and is expressed through the body and works of the CIE (16).

\section{The Standard Eye and Eye Effects}

It has been found that most people (about 90 per cent) perceive varied light stimuli in a similar way. These people have so-called 'normal' vision. Statistical studies have enabled an 'average' eye (or 'standard' observer) to be defined which is only slightly different from that of people with normal colour vision. The properties of this average eye, the CIE 1931 Standard Eye, have been embodied in numerical tables. Thus, calculations of colour can be performed in a reproducible way by different observers. The Standard Eye has been necessarily defined for a simplified and ideal configuration, in which samples having the same colour co-ordinates (see the paragraph entitled 'Calculation of Colour Coordinates') are viewed simultaneously in a $2^{\circ} \mathrm{com}$ parison field against a black background.

\section{Illumination}

The light with which a sample is illuminated has a definite, though not simple, effect on the sample's perceived colour. Thus, in daylight an object's perceived colour may appear to be different from the same object's appearance when observed in artificial light. It is an advantage to use standard illumination conditions when viewing samples or when performing colour calculations. The calculations reported here have been accomplished using the CIE Standard Illuminant $C$ which represents blue sky light (not sunlight). When viewing conditions are altered, then fresh calculations taking the change into account can easily be made. In general, objects may appear to be the same colour in one light and yet possess different colours in a different light. This should be less of a problem with gold alloys than, for example, with gemstones or organic dyes as the spectral reflectivities of metals do not show irregularities but seem rather to fall into groups with generally smooth distributions.

\section{The Calculation of Colour Co-Ordinates}

The tristimulus values $\mathrm{X}, \mathrm{Y}$ and $\mathrm{Z}$ of an object colour stimulus are defined by the equations:

$$
\begin{aligned}
& X=k \int R(\lambda) S() \bar{x}(\lambda) d \lambda \\
& Y=k \int R(\lambda) S(\lambda) \bar{y}(\lambda) \cdot d \lambda \\
& Z=k \int R(\lambda) S(\lambda) \bar{Z}(\lambda) \cdot d \lambda
\end{aligned}
$$

where:

$S(\lambda)$ is the spectral intensity distribution of the illumination

$\mathrm{R}(\lambda)$ is the spectral reflectivity of the object

$\overline{\mathrm{x}}(\lambda), \overline{\mathrm{y}}(\lambda)$ and $\overline{\mathrm{z}}(\lambda)$ are the colour matching functions of the CIE 1931 Standard Eye and correspond respectively to the spectral sensitivities of the red, green and blue receptors of the human eye $\mathrm{k}=\left\{\int_{\lambda} S(\lambda) \bar{y}(\lambda) \cdot \mathrm{d} \lambda\right\}^{1}$.

The computed quantity $\mathrm{Y}$ is the luminance, that is defined in the introduction. The chromaticity coordinates $\mathrm{x}$ and $\mathrm{y}$ complete the three quantities ( $\mathrm{x}, \mathrm{y}$, $Y)$ required to define the colour stimulus.

The definitions:

$$
x=\frac{X}{X+Y+Z} \quad y=\frac{Y}{X+Y+Z} \quad \dot{Z}=\frac{Z}{X+Y+Z}
$$

are such that:

$$
x+y+z=1
$$

and so it is not necessary to tabulate $z$.

These functions are defined numerically, $R(\lambda)$ by a particular experiment or calculation and the others are standards normally obtained from tables. The integrals must be solved by numerical methods. The CIE recommends the weighted ordinate method which uses approximations of the form:

$$
\mathrm{X}=\mathrm{k} \sum_{\mathrm{k}} \mathrm{R}(\lambda) \mathrm{S}(\lambda) \overline{\mathrm{x}}(\lambda) \cdot \Delta \lambda
$$

where:

$\Delta \lambda$ is a small, constant wavelength interval.

In the present work, the complex refractive index function $\vec{\eta}(\lambda)$ was determined using a high precision automatic nulling spectro-ellipsometer (17) and the reflectivity $R(\lambda)$ was computed. The CIE $x$ and $y$ tristimulus co-ordinates discussed above were then determined using standard tables for the standard observer tristimulus coefficients and spectral distribution of the C illuminant (18). Spectral colours of 100 per cent saturation lie on the periphery of the chromaticity diagram, any point inside the colour space represents a colour that lies between the spec- 
trally pure colours and the white (or achromatic) point inside it (Figure 3).

The reflectivity curves used to determine the CIE chromaticity co-ordinates were derived from the experimentally measured $\bar{\eta}(\lambda)$ values since it was considered that in the ultimate, the colour characteristics would depend essentially upon the optical constants of the metal.

\section{Optical Measurements on \\ Gold-Silver-Copper Alloys}

It has been pointed out, in the above section, that a study of the specular reflection over the visible range could lead to colour specification on the basis of the CIE representation. Furthermore, it was suggested that spectro-ellipsometry would provide accurate optical constants which in turn would provide a basis for assessing the effect of changes such as roughening, scratches or films at the surface of samples. It is pertinent to describe briefly the ellipsometer and its application to the present studies of gold-silver-copper alloys.

Plane-polarised monochromatic light undergoes changes in its polarisation characteristics upon reflection at an interface. Generally, reflection at a metal surface produces elliptically polarised light. Ellipsometry is the measurement of the polarisation characteristics of elliptically polarised light and the technique, especially when applied to clean surfaces, provides a sensitive and tractable way of determining optical constants. The parameters measured are the relative phase change $\Delta$ and relative amplitude change $\psi$ suffered by components perpendicular and parallel to the plane of incidence of the plane-polarised incident beam. For a clean substrate these values depend upon the complex refractive index, and hence upon wavelength: $\bar{\eta}=f(\lambda)$ as indicated above. The determination of $\Delta$ and $\psi$ as a function of wavelength thus enables the calculation of the optical constants. It has been shown that the normal reflectivity or reflection at normal incidence $R_{n}$ is determined by $\bar{\eta}$, so that this quantity is also easily accessible. This route makes colour calculations very flexible indeed.

The apparatus used for the present investigation (Figure 4) shines a collimated polychromatic or 'white' light beam onto the sample at an angle of incidence of $75^{\circ}$. The beam is initially made planepolarised and, by passage through an achromatic quarter-wave device, is made elliptically polarised. It is reflection at the metal surface that restores the light to plane polarisation. The polariser and analyser elements in the system are adjusted, in the present case by a servo device, maintaining the system at a null or balance point. The detection system depends upon a photomultiplier-generated signal derived, via a monochromator, from the reflected light.
The samples, mounted and polished rectangular plaquettes, were always fitted on the specimen table of the ellipsometer and measured immediately after a final rinse with de-ionized water. Organic solvents were avoided for washing and rinsing since they are known to leave very tenacious films on gold (19). Optical alignment of the angle of incidence was accomplished by the autocollimation of a laser beam and angular positioning of the specimen was within $0.025^{\circ}$. The angular settings of the optical axis and ellipsometer moveable arm were reproducible to better than $0.005^{\circ}$.

The true optical constants of a surface are independent of the angle of incidence and can therefore be used to determine the normal reflectivity $R_{n}$. Readings of the analyser and polariser azimuths were taken after the system had reached a balance at each wavelength typically of resolution of $0.01^{\circ}$. A total of 121 wavelengths was used in each run. Calculations of all the relevant quantities were then carried out on a computer using the input data of angle of incidence $\theta$, wavelength $\lambda$ and analyser and polariser settings. Thus the quantities determined were:

$\Delta$ the relative phase change

$\psi \quad$ the relative amplitude change

$\bar{\eta}(\lambda)$ the complex refractive index function

$\bar{\varepsilon}(\lambda)$ the complex dielectric function

$R_{n}(\lambda)$ the normal reflectivity function

from which the following were derived:

the CIE colour co-ordinates $x$ and $y$

the luminance, per cent

the saturation, per cent

the dominant wavelength $\lambda_{\mathrm{d}}$.

It is also possible to develop difference curves and first- and second-derivative functions of these major functions.

\section{Colour Characteristics of Gold-Silver-Copper Alloys}

The results of this study are best presented by distinguishing between single-phase solid solution alloys and duplex-phase alloys. All the alloys are bulk and represent the system after water quenching from $600^{\circ} \mathrm{C}$.

The reflectivity curves of the gold-silver and goldcopper binary alloys are displayed in Figure 5. It can be seen that in both cases the gold spectrum progressively transforms into that of its appropriate partner. Particularly, in the gold-silver system the difference between the gold and silver absorption edges - corresponding to interband transitions - is very considerable. The gold edge is shifted by alloying with silver until it passes out of the visible and into the ultra-violet spectrum. In the case of gold-copper, however, the respective absorption edges are very close together and their mixing by alloying occurs essentially within the visible spectrum. Other changes 


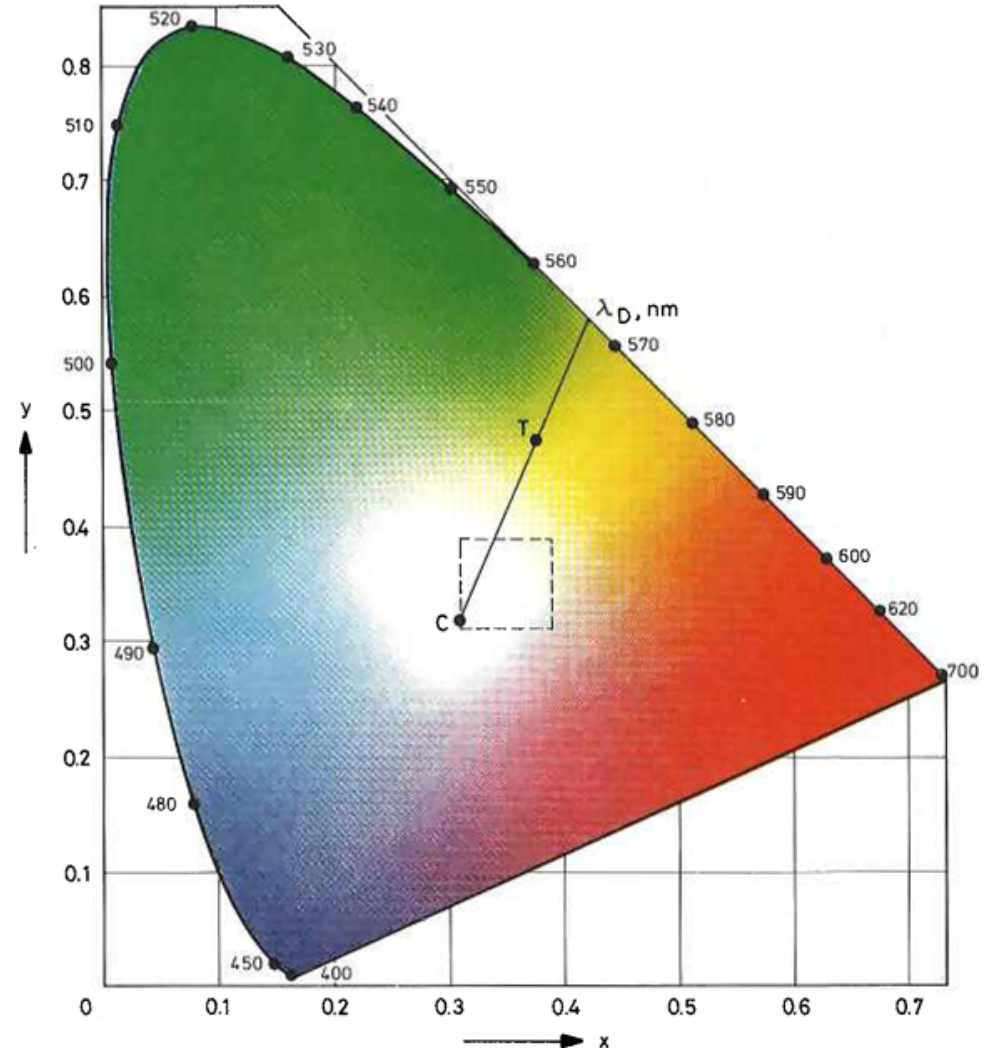

Fig. 3 On the 1931 CIE chromacity chart, the co-ordinates $x$ and $y$ define the chromacity and $Y$, which is not shown on this two-dimensional representation, defines the luminance. The three values $x$, $y$ and $Y$ define the colour. The $C$ illuminant $(x=0.3100, y=0.3162)$ is marked on the diagram. The dominant wavelength $\lambda_{\mathrm{D}}$ of a test point $T$ is given by the intersection of the $\mathrm{C}-\mathrm{T}$ line and the spectrum locus. The saturation is the distance $\mathrm{TC}$ as a percentage of $\mathrm{C} \lambda_{D}$; it is 0 per cent when $T$ falls at $C$ and 100 per cent when $T$ falls at $\lambda_{\mathrm{D}}$. The area covered by Figure 7 is indicated by the dotted line, hence the statement that metals are highly desaturated. After (18)

Reproduced by permission of N.V. Philips' Gloeilampenfabrieken, Eindhoven, Netherlands occur on ordering in this system but are not discussed here since the structure after final heat treatment was in the disordered range. It is fair to say, therefore, that a concomitant feature of solid solutions is the smooth mixing of electron populations from each atomic species as indicated by the optical spectra.

The gold-silver and gold-copper alloy systems differ in one very important aspect - the lattice spacing (Table II). The former shows little variation with composition while the latter does and consequently, effects due to the change of lattice spacing dominate. Furthermore, the variation of CIE co-ordinates with composition (Table III) emphasises that optical phenomena are atomic effects and hence alloys designated in weight percentages will tend to show non-linear variations of 'colour' with composition.

For the silver-copper system (also on Figure 5), the effects of immiscibility are encountered. With these alloys the individual spectra of the components, which are dilute silver and copper terminal solid solutions, remain separate. During alloying, only relative changes in spectral intensities, depending upon the proportion of phases present in the alloy, are distinguishable.

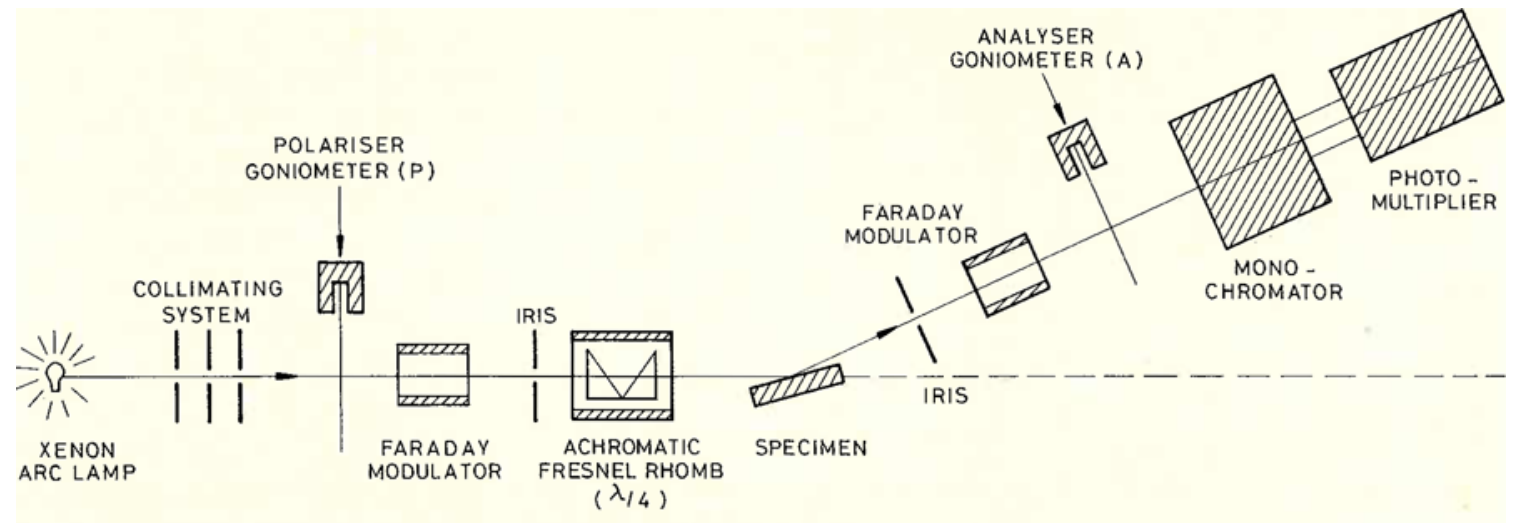

Fig. 4 Diagramatic representation of the spectro-ellipsometer used for this investigation 

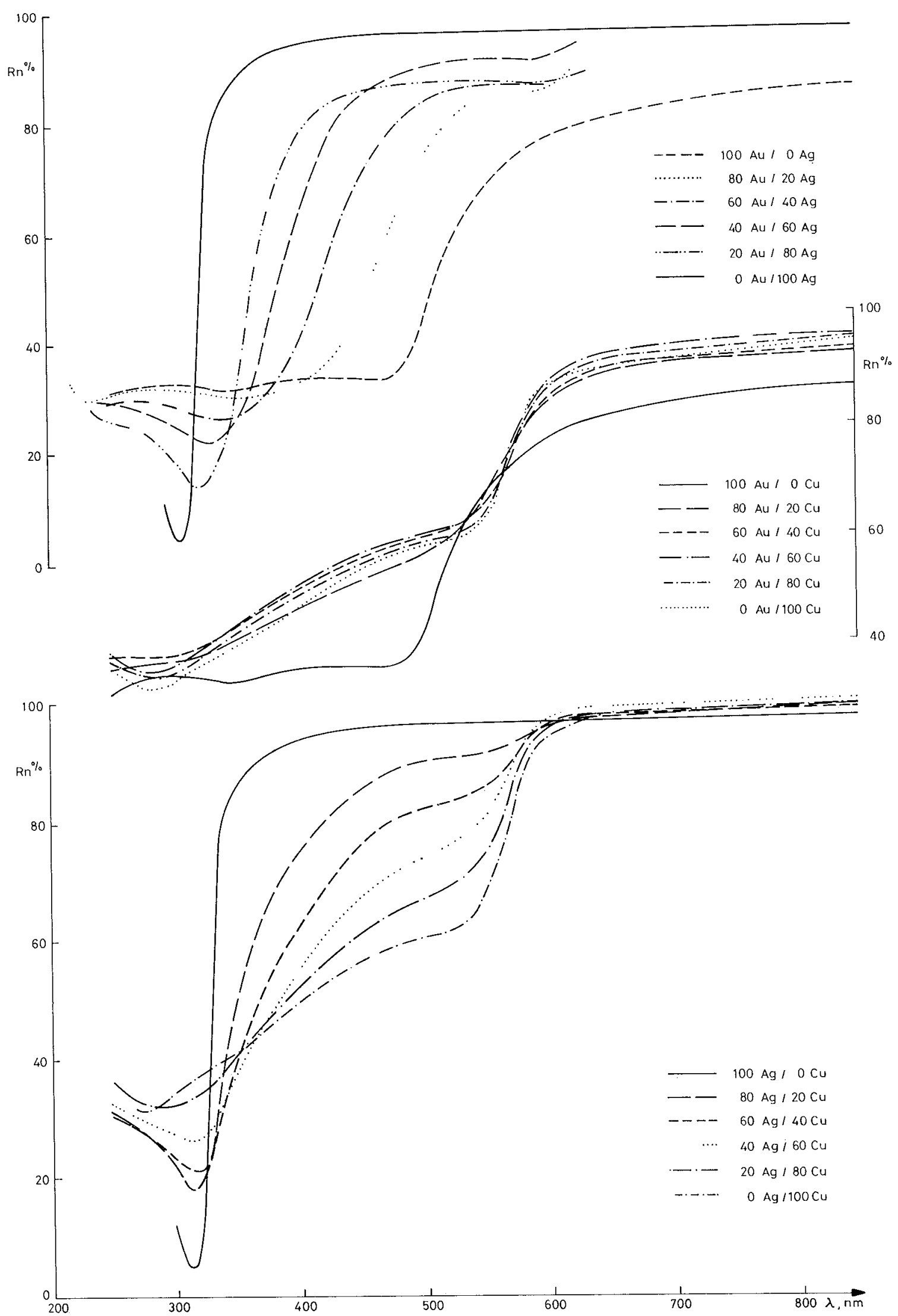

Fig. 5 Normal reflectivity curves $R n(\lambda)$ of gold-silver, gold-copper and silver-copper binary alloys water quenched from $600^{\circ} \mathrm{C}$ 
The reflectivity curves of the ternary alloys exhibit the same basic type of behaviour although, as would be expected here, the silverrich and copper-rich phases derived from the silver-copper system are now alloyed with gold and show shifts in their absorption edges as described for the binary solid solutions. Where the ternary two-phase boundary is crossed, there are appropriate changes in the spectra of single-phase to duplex-phase alloys. Figure 6 shows reflectivity spectra for constant gold contents close to 8,12 and 18 carat. The CIE coordinates of these alloys are shown in Figure 7. The luminosity is not shown since this would require the CIE colour space to be threedimensional; the values were however determined. It is seen that the alloy system still occupies a triangular area but that the triangle, essentially of equal weight percentages, is now severely distorted. The silver-rich alloys all tend to lie together, close to the illuminant white point; a similar effect is noted among the copper-rich alloys. The addition of silver or copper to gold, however, produces profound effects both in hue - which may be regarded as variations circumferentially around the white point - and of saturation - which changes along the radius through the white point. The dominant wavelength of a particular co-ordinate is the wavelength at the intersection of the spectral locus with the line from the white point through the coordinate. It can be clearly seen that the addition of silver to gold makes the resulting alloys progressively more yellow and then green but that the saturation gets progressively lower, that is the colours are more diluted with white. The change when copper is added to gold is similar but in the direction of red and is accompanied by very marked falls in saturation. The silver-copper alloys show effects due to phase mixtures but the colours are very de-saturated.

\begin{tabular}{|c|c|c|c|c|c|}
\hline \multicolumn{6}{|c|}{$\begin{array}{l}\text { Table Ill } \\
\text { CIE (Illuminant C 1931) Colour Co-Ordinates of Binary } \\
\text { and Ternary Alloys in the Gold-Silver-Copper System }\end{array}$} \\
\hline \multirow{2}{*}{$\begin{array}{l}\text { Alloy } \\
\text { No. }\end{array}$} & \multicolumn{2}{|c|}{ Co-ordinates } & \multirow{2}{*}{$\begin{array}{l}\text { Satura- } \\
\text { tion } \\
\%\end{array}$} & \multirow{2}{*}{$\begin{array}{l}\text { Dominant } \\
\text { wavelength } \\
\text { nm }\end{array}$} & \multirow{2}{*}{$\begin{array}{l}\text { Luminance } \\
\%\end{array}$} \\
\hline & $\mathrm{x}$ & $\mathrm{y}$ & & & \\
\hline $1 \mathrm{R}$ & 0.3583 & 0.3376 & 18.68 & 588.9 & 71.09 \\
\hline 2 & 0.3559 & 0.3366 & 17.77 & 588.8 & 70.47 \\
\hline 3 & 0.3539 & 0.3358 & 17.02 & 588.8 & 69.26 \\
\hline 4 & 0.3533 & 0.3355 & 16.78 & 588.8 & 69.37 \\
\hline 5 & 0.3517 & 0.3346 & 16.13 & 589.0 & 70.16 \\
\hline 6 & 0.3506 & 0.3348 & 15.87 & 588.5 & 68.07 \\
\hline 7 & 0.3501 & 0.3360 & 16.04 & 587.5 & 69.94 \\
\hline 8 & 0.3508 & 0.3369 & 16.47 & 587.1 & 69.05 \\
\hline $9 \mathrm{R}$ & 0.3598 & 0.3464 & 21.45 & 584.6 & 68.87 \\
\hline $10 \mathrm{R}$ & 0.3620 & 0.3483 & 22.57 & 584.3 & 69.34 \\
\hline $11 \mathrm{R}$ & 0.3779 & 0.3770 & 34.53 & 579.1 & 65.01 \\
\hline 12 & 0.3154 & 0.3220 & 3.00 & 576.4 & 95.33 \\
\hline 13 & 0.3196 & 0.3245 & 4.79 & 579.7 & 91.28 \\
\hline 14 & 0.3253 & 0.3264 & 6.83 & 583.3 & 86.77 \\
\hline 15 & 0.3307 & 0.3316 & 9.67 & 581.8 & 86.90 \\
\hline 16 & 0.3385 & 0.3372 & 13.28 & 581.9 & 84.45 \\
\hline 17 & 0.3434 & 0.3383 & 14.88 & 583.4 & 83.81 \\
\hline 18 & 0.3490 & 0.3408 & 17.06 & 584.1 & 80.22 \\
\hline 19 & 0.3505 & 0.3399 & 17.21 & 585.1 & 79.68 \\
\hline 20 & 0.3579 & 0.3407 & 19.41 & 587.0 & 74.12 \\
\hline 21 & 0.3679 & 0.3873 & 34.59 & 574.8 & 80.81 \\
\hline 22 & 0.3558 & 0.3783 & 28.96 & 573.5 & 81.56 \\
\hline 23 & 0.3420 & 0.3635 & 21.27 & 572.3 & 85.43 \\
\hline 24 & 0.3278 & 0.3451 & 12.54 & 571.1 & 85.51 \\
\hline 25 & 0.3211 & 0.3332 & 7.54 & 571.9 & 90.06 \\
\hline 26 & 0.3177 & 0.3268 & 4.91 & 573.2 & 90.53 \\
\hline 27 & 0.3157 & 0.3235 & 3.50 & 574.3 & 90.46 \\
\hline 28 & 0.3129 & 0.3197 & 1.70 & 575.0 & 87.29 \\
\hline $29 \mathrm{R}$ & 0.3128 & 0.3193 & 1.58 & 576.5 & 93.71 \\
\hline $30 \mathrm{R}$ & 0.3110 & 0.3173 & 0.57 & 577.1 & 95.86 \\
\hline 31 & 0.3602 & 0.3595 & 25.08 & 579.6 & 72.56 \\
\hline 32 & 0.3545 & 0.3495 & 20.87 & 581.7 & 75.37 \\
\hline 33 & 0.3538 & 0.3619 & 24.01 & 577.0 & 78.24 \\
\hline 34 & 0.3464 & 0.3591 & 21.27 & 575.3 & 80.95 \\
\hline 35 & 0.3506 & 0.3528 & 20.72 & 579.0 & 76.21 \\
\hline 36 & 0.3537 & 0.3451 & 19.46 & 583.4 & 71.51 \\
\hline 37 & 0.3392 & 0.3529 & 17.70 & 574.5 & 82.63 \\
\hline 38 & 0.3430 & 03495 & 17.77 & 577.5 & 80.47 \\
\hline 39 & 0.3478 & 0.3462 & 18.21 & 580.8 & 76.89 \\
\hline 40 & 0.3515 & 0.3418 & 18.00 & 584.4 & 72.14 \\
\hline 41 & 0.3312 & 0.3432 & 12,94 & 574.3 & 85.16 \\
\hline 42 & 0.3348 & 0.3410 & 13.28 & 577.6 & 83.53 \\
\hline 43 & 0.3401 & 03406 & 14.61 & 580.5 & 79.34 \\
\hline 44 & 0.3447 & 0.3402 & 15.74 & 582.8 & 76.72 \\
\hline 45 & 0.3500 & 0.3418 & 17.58 & 583.9 & 74.46 \\
\hline $45 \mathrm{R}$ & 0.3519 & 0.3411 & 17.89 & 584.9 & 72.33 \\
\hline 46 & 0.3310 & 0.3356 & 10.82 & 578.7 & 81.22 \\
\hline $46 \mathrm{R}$ & 0.3276 & 0.3401 & 11.12 & 573.5 & 90.34 \\
\hline 47 & 0.3293 & 0.3352 & 10.28 & 577.8 & 84.81 \\
\hline 48 & 0.3334 & 0.3353 & 11.42 & 580.4 & 82.91 \\
\hline 49 & 0.3404 & 0.3378 & 13.94 & 582.4 & 77.99 \\
\hline 50 & 0.3466 & 0.3381 & 15.68 & 584.8 & 74.49 \\
\hline 51 & 0.3497 & 0.3378 & 16.30 & 586.5 & 73.13 \\
\hline 52 & 0.3224 & 0.3310 & 7.29 & 575.2 & 86.83 \\
\hline 53 & 0.3265 & 0.3327 & 8.85 & 577.6 & 85.49 \\
\hline 54 & 0.3306 & 0.3331 & 10.05 & 580.4 & 83.64 \\
\hline 55 & 0.3336 & 0.3338 & 11.04 & 581.7 & 82.46 \\
\hline 56 & 0.3419 & 0.3375 & 14.25 & 583.3 & 76.01 \\
\hline 57 & 0.3452 & 0.3364 & 14.86 & 585.4 & 76.09 \\
\hline 58 & 0.3511 & 0.3374 & 16.70 & 586.9 & 72.60 \\
\hline 59 & 0.3184 & 0.3254 & 4.72 & 576.4 & 87.76 \\
\hline 60 & 0.3231 & 0.3268 & 6.35 & 580.5 & 86.66 \\
\hline 61 & 0.3271 & 0.3290 & 8.02 & 581.6 & 85.20 \\
\hline 62 & 0.3325 & 0.3311 & 10.02 & 583.4 & 81.08 \\
\hline 63 & 0.3488 & 0.3376 & 16.14 & 585.9 & 72.13 \\
\hline 64 & 0.3437 & 0.3366 & 14.51 & 584.6 & 74.95 \\
\hline 65 & 0.3360 & 0.3349 & 11.98 & 582.3 & 79.76 \\
\hline 66 & 0.3536 & 0.3376 & 17.42 & 587.5 & 71.76 \\
\hline
\end{tabular}




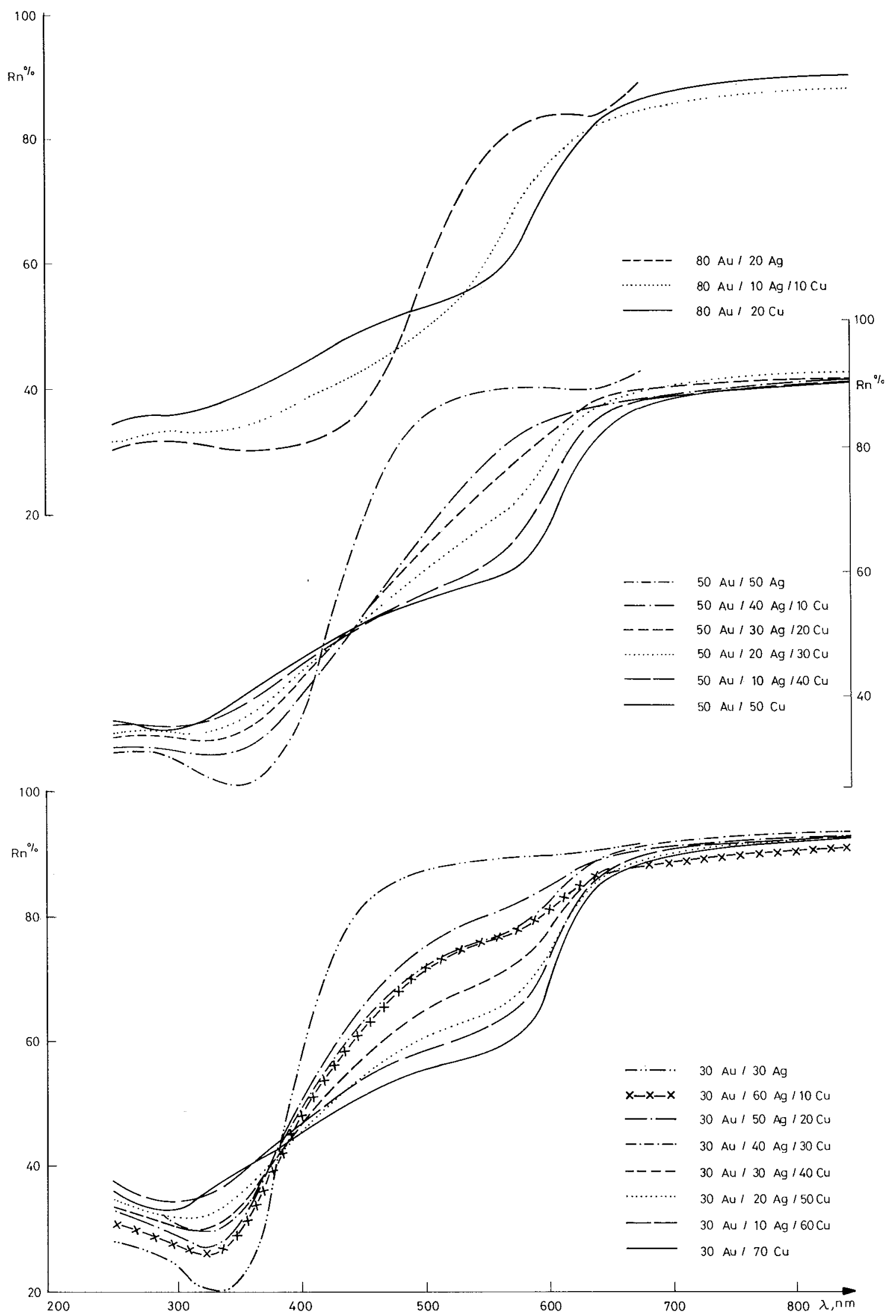

Fig. 6 Normal reflectivity curves $R n(\lambda)$ of ternary gold-silver-copper alloys at the constant gold contents of 30, 50 and 80 weight per cent. The alloys were all water quenched from $600^{\circ} \mathrm{C}$ 
Fig. 7 CIE co-ordinates $x$ and $y$ (chromacity) of binary and ternary alloys in the gold-silvercopper system after water quenching from $600^{\circ} \mathrm{C}$. The dots correspond to actual measurements on the 66 alloys prepared for this investigation while the dotted lines are extrapolated

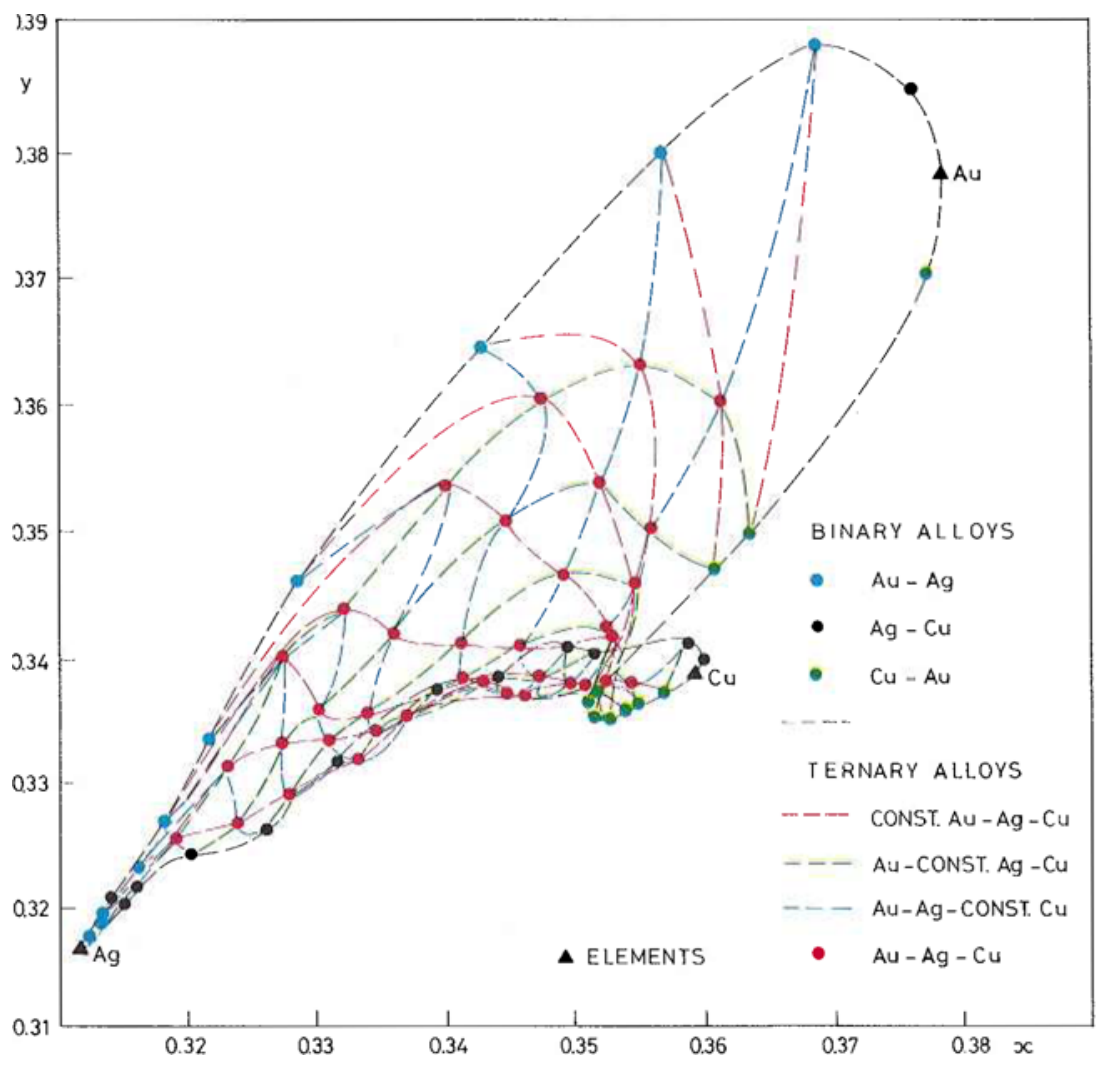

(5) All the alloys measured show low saturation, a limited range of dominant wavelengths and high luminance. Such features are typical of metallic reflections and limit the range of colours required for normal assessment of jewellery alloy colours.

\section{Acknowledgements}

The authors gratefully acknowledge the support given to them during this work by the Worshipful Company of Goldsmiths Research Foundation and the International Gold Corporation Limited. They would also like to thank Messrs. Reuben Cohen and Robert Hunt for their painstaking preparation and measurement of alloys. Finally, they wish to express their gratitude to the ILEA, City of London Polytechnic and Dr. L. L. Shreir of the Department of Metallurgy for the use of extensive computing and laboratory facilities without which this contribution to the gold industry would not have been possible.

\section{References}

1 W. S. Rapson and T. Groenewald, 'Gold Usage', Academic Press, London, 1978, 31-41 and 77-81

2 J. Leuser, Metall, 1949, 3, 105-110, 128

3 G. Tammann, Nachr. Götting. Ges., 1917, 345-384

4 G. Tammann, Z. anorg. allg. Chem., 1919, 107, 1-240

5 'Gold: Recovery, Properties and Applications', ed. by E. $M$ Wise, D. Van Nostrand Co. Inc., Princeton, N.J., 1964, 262 6 G. E. Gardam, Trans. Inst. Met. Finish., 1964, 41, 190-199

7 G. E. Gardam, Trans. Inst. Met. Finish, 1966, 44, 186-188

8 W. Köster and R. Stah1, Z. Metallkd., 1967, 58, 768-777

9 R. Stahl, H. J. Spranger and H. P. Aubauer, Z. Metallkd., 1969, 60, 933-943

10 J. Rivory, f. Phys. Paris, 1974, 35, (5), C4-51 - C4-56

11 D. E. Weiss and L. Muldawer, Phys. Rev. B, 1974, 10, (6), 2254-2260
12 A. S. McDonald and G. H. Sistare, Gold Bull., 1978, 11, (3), 66-73

13 J. G. McMullin and J. T. Norton, Trans. Am. Inst. Min Metall. Eng., 1949, 1, 46

14 R. W. Ditchburn, 'Light', Black1e and Sons Ltd., London, 1963

15 E. P. Lavin, 'Specular Reflection', Adam Hilger, London, 1971

16 'CIE International Lighting Vocabulary, 3rd Edition', CIE, Paris, 1970

17 E. F. I. Roberts and A. Meadows, F. Phys.: E., 1974, 7, 379-385

18 P. J. Bouma, 'Physical Aspects of Colour', Macmillan and Co. Ltd., London, 1971

19 E. F. I. Roberts, Gold Bull., 1973, 6, (2), 42-45 